\title{
Hydrogen-bonded Encapsulation Complexes in Protic Solvents
}

Toru Amaya and Julius Rebek, Jr.*

The Skaggs Institute for Chemical Biology and Department of Chemistry, The Scripps Research Institute, 10550 North Torrey Pines Road, La Jolla, California 92037 U.S.A.

\section{Supporting Information}

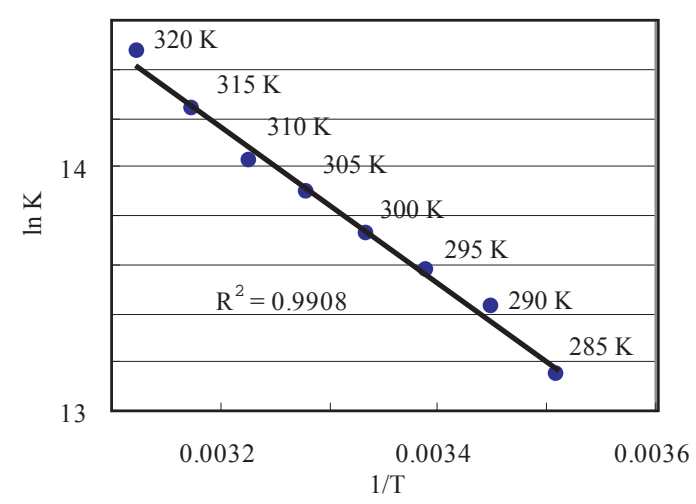

Figure S1. Van't Hoff plot for $10 \%$ methanol- $d_{4}\left(\mathrm{v} / \mathrm{v}\right.$ in mesitylene- $\left.d_{12}\right)$ : $[\mathbf{1}]_{\text {total }}=2 \mathrm{mM}$, $[\mathbf{8}]_{\text {total }}$ $=25 \mathrm{mM}$, methanol- $d_{4}+$ mesitylene- $d_{12}=600 \mu \mathrm{L}$.

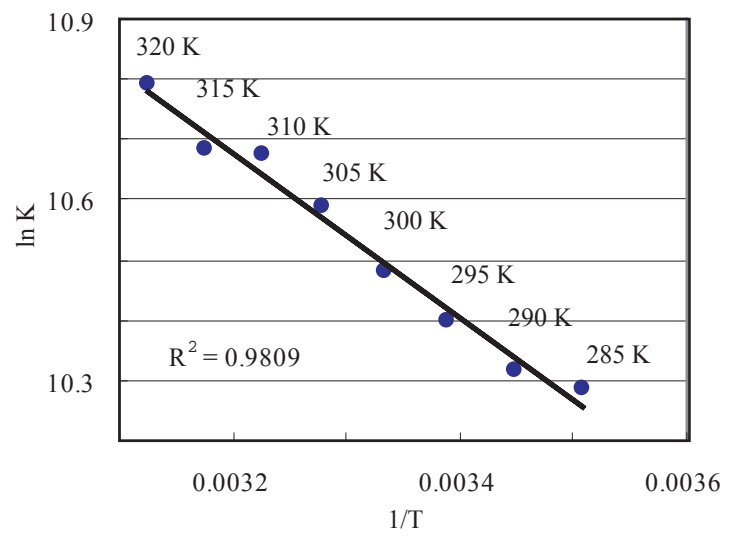

Figure S2. Van't Hoff plot for $30 \%$ methanol- $d_{4}\left(\mathrm{v} / \mathrm{v}\right.$ in mesitylene- $\left.d_{12}\right)$ : $[\mathbf{1}]_{\text {total }}=2 \mathrm{mM},[\mathbf{8}]_{\text {total }}$ $=25 \mathrm{mM}$, methanol- $d_{4}+$ mesitylene- $d_{12}=600 \mu \mathrm{L}$. 


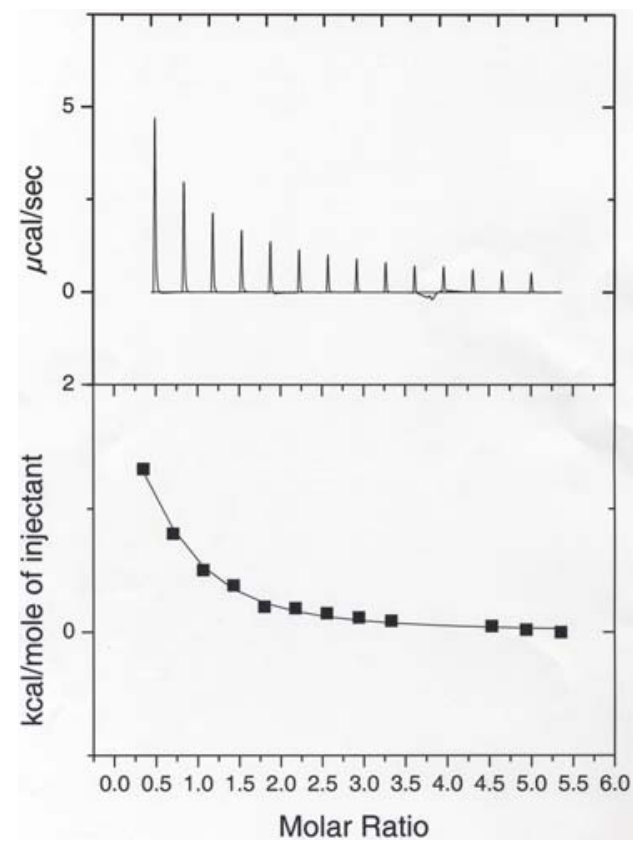

Figure S3. Isothermal titration calorimetry (ITC) data: ITC experiment was carried out as follows: the solution of $\mathbf{1}(0.4 \mathrm{mM})$ in $10 \%$ methanol (v/v in mesitylene) was titrated with guest 8 (4.0 mM in the same solvents). However, we couldn't find a proper fitting curve program to calculate thermodynamic parameters for the case of 2:1 (= host:guest) complex with the available software (Origin 7.0 software, MicroCal, LLC). 